\title{
Assessment of Physical, Microstructural, Thermal, Techno-Functional, And Rheological Characteristics of Apple (Malus Domestica) Seeds of Northern Himalayas
}

Mehnaza Manzoor ( $\nabla$ mehnazmanzoor321@gmail.com )

Sher-e-Kashmir University of Agricultural Sciences and Technology of Jammu Jagmohan Singh

Sher-e-Kashmir University of Agricultural Sciences and Technology of Jammu

\section{Research Article}

Keywords: morphological, Thermograph, macromolecules, electron micrographs

Posted Date: August 5th, 2021

DOl: https://doi.org/10.21203/rs.3.rs-770178/v1

License: (9) (1) This work is licensed under a Creative Commons Attribution 4.0 International License.

Read Full License

Version of Record: A version of this preprint was published at Scientific Reports on November 23rd, 2021. See the published version at https://doi.org/10.1038/s41598-021-02143-z. 


\section{Corresponding author:}

\section{Abstract}

\section{Introduction}

\section{Assessment of physical, microstructural, thermal, techno-functional, and rheological} characteristics of apple (Malus domestica) seeds of Northern Himalayas

Mehnaza Manzoor ${ }^{1 . *}$, Jagmohan Singh ${ }^{1}$

${ }^{1}$ Division of Food Science and Technology, Sher-e-Kashmir University of Agriculture Science and Technology, Jammu,180009, India

\section{mehnazmanzoor321@gmail.com}

The study examined the physical, morphological, thermal, techno-functional, and rheological properties of two apple seed cultivars viz: red delicious (RD) and golden delicious (GD). Physical properties showed that red delicious seeds were significantly $(\mathrm{p} \leq 0.05)$ different in width, geometric mean diameter, arithmetic mean diameter, volume, and surface area than golden delicious seeds. The proximate composition of RD seed flour showed a higher amount of crude protein and fat content than GD seed flour. RD seed flour was significantly different in $\mathrm{L}^{*}, \mathrm{a}^{*}, \mathrm{~b}^{*}$ values, bulk density, water/oil absorption capacity and the emulsifying ability than GD seed flour. From particle size analysis it was possible to found that GD was significantly $(p \leq 0.05)$ lower than RD flour macromolecules. Scanning electron micrographs showed oval/spherical starch granules of small size embedded in a continuous protein matrix. Thermograph revealed exothermic transition enthalpy for both RD and GD seed flour, which indicates a high energy requirement for crystallite melting. The rheological assays revealed high elastic modulus $\left(\mathrm{G}^{\prime}\right)$, of seed flours that will help in modifying the texture of foods. This study suggests the potential of apple seeds in the formulation of proteinenriched foods to combat malnutrition while contributing to the reduction in industrial wastage.

Apple (Malus domestica) is one of the most important fruit crops cultivated throughout the temperate regions of the world. The fruit is consumed fresh or processed into products such as juice, concentrate, jam, cider, canned products. However, processing of apples generate huge quantum of pomace accounting for up to 20-35\% share of fresh fruit weight and consists primarily of a mixture of skin/ pulp tissue $(94.5 \%)$, with a significant amount of seeds $(4.1 \%)$ and stems $(1.1 \%)^{1,2}$. Apple seeds are reported to be excellent sources of protein (38.85-49.55\%) and lipids (20.69-24.32\%) with linoleic and oleic acids as predominant amino acids ${ }^{3}$. The seeds also contain a considerably high amount of polyphenols which contribute to reducing the risk of obesity and diabetes mellitus ${ }^{4-6}$, help prevent bone loss, inhibit cancer cell growth, enhance memory, and life span ${ }^{6}$. They are also rich sources of natural antioxidants and can inhibit lipid peroxidation ${ }^{4}$. Currently, the seeds are gaining more interest 
in food formulations and as potential delivery material for the administration of bioactive compounds 6 .

Moreover, depending on the variety, apple seeds vary in shape size, and color. The knowledge of the geometrical properties of seeds could be useful to separate seeds into different fractions for further post-harvest processing and to further select the high-quality fractions in terms of nutritional and functional value. Although many studies have determined physical and mechanical characteristics of agricultural materials such as tung (Aleurites fordii) seeds ${ }^{7}$, melon (Cucumis melo L.) seeds $^{8}$, sunflower (Helianthus annuus) seeds ${ }^{9}$, Akee apple (Bilphia sapida) seed ${ }^{10}$, oats (Avena sativa L.) ${ }^{11}$, finger millet (Eleusine coracana) ${ }^{12}$, no such study has been carried out for apple seeds. Besides, there is no study on the thermal, morphological, and rheological properties of apple seed flours. Due to the lack of such studies, apple seeds are rarely used at the commercial level and they generally goes waste. The work was thus focused to determine the basic geometrical, morphological, thermal, techno-functional, and rheological properties of underutilized apple seeds collected from two varieties (red delicious and golden delicious) of Himalayan origin to feed the growing functional food industry.

\section{Results and Discussions}

\subsection{Physical characterization of apple seeds}

Physical dimensions measured in terms of length, width, thickness, arithmetic, and geometric mean diameter, and shape provide valuable information for differentiating between varieties and/or other grains and in designing material handling and processing machinery. Results of the physical characterization of flour samples are presented in Table 1. The length, width, and thickness of apple seeds varied significantly, with length ranging from $7.69 \mathrm{~mm}$ (GD) to $9.43 \mathrm{~mm}$ (RD), seed width in a range of $4.02 \mathrm{~mm}(\mathrm{GD})$ to $4.87 \mathrm{~mm}(\mathrm{RD})$, and thickness in a range of $2.01 \mathrm{~mm}(\mathrm{RD})$ to $2.03 \mathrm{~mm}$ (GD), respectively. The arithmetic mean diameter and geometric mean diameter of seeds measured were also found to vary significantly and were $4.58 \mathrm{~mm}, 5.44 \mathrm{~mm}$, and $3.97 \mathrm{~mm}, 4.51 \mathrm{~mm}$ respectively, for GD and RD cultivars. Similar results were obtained on Sabzar, SKO20, and SKO90 oats as reported by Shah et al. ${ }^{11}$ with length ranging from 8.2 to 9.03 , width 1.50 to 1.73 , and thickness 2.25 to 2.66, and geometric and arithmetic diameters varying from 3.12 to 3.40 and 4.07 to $4.33 \mathrm{~mm}$ respectively. Seed surface area, which determines the shape of seed and is considered important in heat and mass transfer operations ${ }^{9}$ and ranged from $49.57 \mathrm{~mm}^{2}$ to $64.19 \mathrm{~mm}^{2}$. It was found that the lowest volume was occupied by golden delicious variety $\left(20.22 \mathrm{~mm}^{3}\right)$ compared to red delicious $\left(29.08 \mathrm{~mm}^{3}\right.$ ). Similarly, sphericity ranged from $48.18 \%$ (RD) to $51.72 \%$ (GD) indicating a higher resemblance of golden delicious seeds towards a sphere. This can be attributed to the higher moisture content of GD seeds compared to RD. The increase in sphericity with increased moisture content was reported by Malik \& Saini $^{9}$ in sunflower seeds. Besides, sphericity and length are inversely related, with round grains resembling more to a sphere than a cylinder. Similar relations were depicted in our study with more spherical grains having the lowest length. However, both 
varieties depicted non-significant variation in aspect ratio, which indicates the tendency of seeds to roll on a flat surface. Also, the thousand-grain weight, which usually indicates the endosperm content in the seeds, was found to be $44.83 \mathrm{~g}$ (GD) and $45.32 \mathrm{~g}$ (RD) with no significant difference noticed between cultivars. All such variations could be attributed to the genetic makeup of the seed cultivars and will play an important role in the machine and other post-harvest equipment designing for efficient handling, processing, and storage of materials.

\subsection{Chemical composition of seed flour}

Table 2 presents the proximate analysis such as moisture, crude fat, protein, and total ash content of red delicious and golden delicious seed flour. Moisture content is an important parameter that can help suggest the storage stability of dried products. Higher moisture content tends to shorten the shelf life and result in loss of physical, chemical, biochemical properties, and as well as results in rapid microbial growth ${ }^{12}$. The results for moisture content were found to be $8.17 \%$ for RD and $8.57 \%$ for GD seed flour with no significant variation observed among cultivars. These results were agreeable to that reported for Akee apple seed flour $(8.05 \%)^{10}$. It was also found that RD flour contained significantly high $(\mathrm{p} \leq 0.05)$ crude protein and fat content. The crude protein content was found to be $41.31 \%$ (GD) and $47.98 \%$ (RD) and was higher compared to other fruit seeds such as kiwi fruit flour $(4.75-8.74 \%)^{13}$, quinoa flour $(13.46 \%)^{14}$, watermelon, guava, orange, apricot, paprika and prickly-pear ${ }^{15}$ and also protein-rich flours, such as chickpea $(20-24.3 \%)^{16}$, cowpea $(24.1 \%)$ and horse gram flour $(22.5 \%)^{17}$. This high protein content might be substantial enough to have a decisive effect for supplementing composite flours for the development of nutrient-enriched food products. Regarding protein quality, apple seeds are reported to be rich in sulfur-containing amino acids and appear to be reasonably balanced, with most of the essential amino acids above the FAO/WHO pattern (FAO/WHO, 1993). Concerning lipid content, a significantly highest percentage was found in RD cultivar $25.31 \%$ than GD cultivar $21.47 \%$. These results are comparable to that reported for $L$. acidissima (Wood apple) seed flour $(24.9 \%)^{18}$ but superior to that reported for quinoa seed flour which has only $5.47 \%$ oil $^{14}$. However, total ash content, which is related to minerals, was not found to vary significantly and was found to be $4.35 \%$ (RD) and $4.67 \%$ (GD). These results were found to be higher than in C.lanatus $(2.75 \%)$ and L. acidissima (2.84\%) seed flour ${ }^{18}$. Overall, flours presented a good nutritional value that can contribute to the formulation of protein-enriched functional foods to combat malnutrition.

\subsection{Flour flowability properties}

\subsubsection{Bulk density, True density, Carr's index, and Hausner ratio}

The bulk density, which indicates the load flour samples can withstand if allowed to rest directly on one another ${ }^{12}$ was recorded to be $0.38 \mathrm{~g} / \mathrm{ml}$ and $0.60 \mathrm{~g} / \mathrm{ml}$ for RD and GD cultivars (Table 3). This variation in bulk density can be associated with particle size, with finer particles resulting in higher bulk density since particles orient in a manner to decrease inter practical space to occupy less space compared to coarse particles. These results can also be validated from particle size distribution and 
SEM results which depict a larger size of RD cultivar resulting in reduced mass per unit volume occupied by flour sample compared to GD flour. The higher bulk density value of GD flour can also be attributed to its high moisture content that increases total mass per unit volume occupied by flour sample. The true density was found higher than bulk density with mean measured values of $0.58 \mathrm{~g} / \mathrm{mL}$ for RD and $0.69 \mathrm{~g} / \mathrm{mL}$ for GD. For good flowability of powdered samples, bulk and true density values should be close enough to have a lower Carr index. The Carr compressibility index of RD and GD flour was found to be $34.51 \%$ and $37.70 \%$ while the Hausner ratio was found to be $1.52 \%$ and $1.6 \%$ respectively (Table 3 ). Carr index $>25 \%$ is considered to be a poor flowability indicator, and $<$ $15 \%$ a good flowability indicator ${ }^{18}$. These results are in line with the findings of Sonawane et al. ${ }^{18}$ where bulk and true densities measured were $0.26,0.28 \mathrm{~g} / \mathrm{ml}$ and $0.39,0.47 \mathrm{~g} / \mathrm{ml}$, which resulted in compressibility index of $34.17 \%$ and $41.27 \%$ for C. lanatus and L. acidissima flour respectively.

\subsection{Particle size distribution and polydispersity index}

Particle-size distribution is a quality parameter influencing the processing performance of flour samples. Table 3 shows the average hydrodynamic diameter and particle size distribution of flour samples in aqueous suspension. The particle sizes of GD at 10\% (Dv10), 50\% (Dv50), and 90\% (Dv 90) volume distribution was found to be $2.603,4.419$, and $6.122 \mu \mathrm{m}$ respectively, which was lower than corresponding values for $\mathrm{RD}$ cultivar $(6.269,7.580$ and $9.060 \mu \mathrm{m})$. Moreover, the average hydrodynamic diameter of GD and RD flour fractions was found to be $2.97 \mu \mathrm{m}$ and $8.73 \mu \mathrm{m}$ respectively which indicates that these macromolecules were finely ground with varying particle size depended on seed cultivar. It has already been stated that difference in particle size distribution among different flours might depend on endosperm structure (hard or soft), the grade of material, endosperm cells, and grinding equipment used ${ }^{19}$. Besides, the polydispersity index which reflects homogeneity of sample based on size was found to be 0.12 and 0.43 for GD and RD seed flours respectively, and around 0.4 indicates narrow size distribution of sample particles with good stability in solution ${ }^{20}$.

\subsection{Color}

Color, an important quality attribute, immensely influences the consumers' preference and choice of food. The results of the color characteristics (table 4) of both flours presented satisfactory whiter color with higher brightness values $\left(L^{*}\right)>75$. The significantly $(p \leq 0.05)$ higher $L^{*}$ value of GD flour may be attributed to its reduced particle size (as also reported from SEM results) as compared to RD flour, increasing surface area and thereby allowing greater reflection of light. The lower $\mathrm{a}^{*}$ values in both flour samples which is an indication of greenness also displayed a significant ( $\mathrm{p} \leq 0.05$ ) difference among varieties with red delicious presenting more greenness than golden delicious. Similarly, $b^{*}$ values which indicate blueness and yellowness ranged from 9.18 to 10.64 with a lower value of yellowness for RD seed flour which may be due to a reduction in pigments during processing. Lightness and yellowness are important color attributes that influence consumers' preference and acceptability of products ${ }^{12}$. These results are comparable to those reported by Kaur \& Singh ${ }^{16}$ who studied the variation in color in different varieties of chickpea flour. Such variations in 
color characteristics may also result from differences in inherent colored pigment among the flour varieties, resulting from genetic variations of the seeds.

\subsection{Scanning electron microscopy (SEM)}

The morphological structures of both apple seed flour are depicted in Fig 1a and 1b. The SEM morphograph revealed the presence of small and as well as large starch particles of varying shapes and dimensions with some dents/fissures. The starch macromolecules were embedded in a continuous matrix formed by proteins and other non-protein components. The micrograph indicated that starch granules in red delicious seed flour form clusters and were semi-spherical, oval-shaped, and polygonal with a rough surface and size ranging from 4.56-15.27 $\mu \mathrm{m}$ (Fig 1b). However, golden delicious (Fig 1a.) depicted spherical, oval-shaped, and somewhat irregular but smooth-surfaced starch granules with sizes ranging from 2.04-14.32 $\mu \mathrm{m}$ very similar to results for oat flour ${ }^{11}$. These changes in conformation, as well as shape and size distribution of starch granules, could influence the functionality of seed flours for their further use in functional food development.

\subsection{Thermal characterization of apple seed flours}

The thermal characteristics of two seed flours as determined by DSC differed significantly ( $p$ $\leq 0.05$ ). The gelatinization transition temperatures (onset temperature, To, endothermic peak temperature, $\mathrm{Tp}$ and conclusion temperature, $\mathrm{Tc})$ and enthalpy of gelatinization $(\Delta \mathrm{H})$ of two seed flour samples were determined by DSC. The values obtained for Golden and red delicious seed flours were $\mathrm{Tp}=98.37,102.17^{\circ} \mathrm{C}, \mathrm{To}=78.95,89.07^{\circ} \mathrm{C}, \mathrm{Tc}=108.71,117.53{ }^{\circ} \mathrm{C}$ and $\Delta \mathrm{H}=18.41,9.78 \mathrm{~J} / \mathrm{g}$ respectively (Table 4). Results revealed that gelatinization temperatures of red delicious were significantly $(\mathrm{p} \leq 0.05)$ higher than golden delicious variety. As already stated, gelatinization transition temperatures vary with botanical species and usually differ with shape, size, and the internal arrangement of starch fractions within granule ${ }^{16}$. At the same time, the higher endothermic peak temperature of red delicious flour as compared to golden delicious variety $(\mathrm{p} \leq 0.05)$ might be attributed to its high proteins, lipids, and fiber content that gets degraded at high temperature ${ }^{21}$. Further, a significant $(\mathrm{p} \leq 0.05)$ difference in the gelatinization enthalpy was also recorded among the two cultivars with red delicious flour having generally lower $\Delta \mathrm{H}$ value $(9.78 \pm 1.33 \mathrm{~J} / \mathrm{g})$ compared to golden delicious seed flour $(18.41 \pm 0.63 \mathrm{~J} / \mathrm{g})$ indicating its low energy requirement for crystallite melting. It may be due to a greater number of double-helical regions within golden delicious granules which require more energy for breaking hydrogen bond between glucan chains for complete starch gelatinization. Further $\operatorname{Ren}^{22}$, reported that particle size also affects $\Delta \mathrm{H}$ value suggesting that flour with small particles result in complete protein denaturation and starch gelatinization which is consistent with the SEM results of this study.

\subsection{Techno-functional properties of flour samples}

The techno-functional properties that have been categorized as non-nutritive food characteristics with a critical contribution in improving the existing functionalities and help in new product development were also investigated with results depicted in Table 4. 


\subsubsection{Water holding capacity}

Water holding capacity determines the ability of a product to hold water depending on the presence of polar/ hydrophilic proteins and polysaccharides ${ }^{16,23}$. The results depicted a significantly ( $p$ $\leq 0.05)$ higher water holding capacity (WHC) of RD (327.65 g/100g) compared to GD (312.58 $\mathrm{g} / 100 \mathrm{~g}$ ). Earlier, El-safy et al. ${ }^{15}$ reported comparable results for the Egyptian variety of apple seed flour $(3.58 \mathrm{~g} / \mathrm{g})$, whereas lower values were found for watermelon, guava, orange, apricot, paprika, and prickly-pear. The existence of higher protein content in flour samples (Table 1) might contribute to their higher WHC. Since it has been reported that the presence of several hydrophilic proteins especially polar amino acid residues bind subsequently with more water molecules resulting in higher water absorption ${ }^{17}$.

\subsubsection{Oil holding capacity}

Regarding oil absorption capacity (OHC), the values observed in the present work $(92.97 \mathrm{~g} / 100 \mathrm{~g}$ and $86.76 \mathrm{~g} / 100 \mathrm{~g}$ for RD and GD respectively) are low compared to values given for the Egyptian variety of apple seeds flour ${ }^{15}$. This variation in fat absorption among two cultivars can be attributed to variation in protein concentration, hydrophobicity of proteins that determine its degree of interaction with oil and water ${ }^{24}$.

\subsubsection{Emulsion activity and stability}

Emulsification activity (EA) characterizes the capacity of flour samples to form stable emulsion via interaction of polar and non-polar proteins with oil droplets at the oil-water interface was recorded to be $79.61 \%$ for $\mathrm{RD}$ and $72.01 \%$ for GD with significant $(\mathrm{p} \leq 0.05)$ difference observed among cultivars. Therefore, more is protein content more will be adsorption ability towards oil. Also, emulsification stability (ES), which indicates if the globular proteins present in the flour sample can prevent deformation of the emulsion system under shear stress conditions ${ }^{17}$ was found to have higher values for $\mathrm{RD}$ flour $(51.81 \%$ ) than GD seed flour $46.56 \%$ after 60 minutes (Table 4). A comparatively lower EA of $47.58 \%$ and $40.60 \%$ and ES of $45.22 \%$ and $11.48 \%$ were reported for $C$. lanatus and L. acidissima seed flours respectively ${ }^{18}$. Therefore high EA and ES will render these flours more suitable for surface adsorption for use in stabilizing colloidal food systems and in processed meat products such as sausages ${ }^{18}$.

\subsection{Dynamic rheology}

The difference in rheological behaviour (visco-elastic properties) of two flour samples was expressed in terms of loss moduli $G^{\prime \prime}$ and storage moduli $G^{\prime}$. Variation curves of $G^{\prime \prime}$ and $G^{\prime}$ as a function of oscillatory frequency are depicted in Figure 2. The mechanical spectra of both samples obtained in this study displayed consistently higher $\mathrm{G}^{\prime}$ than $\mathrm{G}^{\prime \prime}$ throughout the frequency range studied, which indicated typical viscoelastic behaviour with a predominant solid or elastic (gel-like) character. Generally, higher $G^{\prime}$ is an indication of weak gel behaviour. Lower viscous modulus $G^{\prime \prime}$ values compared to elastic modulus $\mathrm{G}^{\prime}$ indicates that flour samples are of good quality which could lead to higher bread loaf volume. Interestingly, Jhan et al. ${ }^{24}$ reported a similar trend of dynamic 
moduli of pearl millet used in their studies. Moreover, red delicious seed flour exhibited a pronounced increase in visco-elastic behavior compared to golden delicious variety. This could be due to the higher protein percentage in red delicious seed flour which favours protein aggregations resulting from increased disulfide linkage and enhanced interaction of gluten network within the matrix favouring visco-elasticity of the continuous phase. The effect of protein in increasing the $\mathrm{G}^{\prime}$ and $\mathrm{G}^{\prime \prime}$ was reported by Marco \& Rosell ${ }^{25}$. The results were also consistent with the proximate composition wherein RD and GD seed flours showed higher protein concentration.

\section{Conclusion}

The study provided a basic understanding of various geometrical, physiochemical, functional, structural, thermal, and rheological properties of two underutilized apple seed cultivars. The seeds showed considerable difference in dimensional properties which will enable the sorting of apple seeds into different fractions for post-harvest operations. Likewise, a significant difference was observed in chemical composition and techno-functional properties with red delicious seed flour having significantly higher water/oil holding capacity, emulsification capacity, and emulsification stability. A considerable good amount of protein and lipid content was observed in seed flours that suggest their use in the development of protein-enriched food products with different end uses. Further, flour prepared from red delicious seeds depicted smaller particle size distribution with higher stability to thermal degradation mostly suitable for various food processing operations. Rheological results revealed predominant visco-elastic behaviour of seed flour which could help modify the texture of foods. These findings will be useful to measure the quality of seeds in terms of nutritional and functional value. Further, the exploitation of apple seeds can be a boon for food security while minimizing industrial food wastage and as well contribute in development of protein-enriched foods to combat malnutrition.

\section{Materials and methods}

\subsection{Materials}

Apple seeds (Golden delicious and Red delicious) were procured from Juice processing industry (FIL Industries Pvt Ltd, Srinagar, J\&K, India). The samples were cleaned, dried, dehulled and then stored at $4{ }^{\circ} \mathrm{C}$ in air tight containers. All chemicals and reagents used were of analytical grade and purchased from High media Laboratories Pvt Ltd and Sigma Aldrich (USA).

\subsection{Sample preparation}

The seed flours were prepared following method described in our previous work ${ }^{4}$.

\subsection{Physical characterization of apple seeds}

\subsubsection{Geometric properties}

The three principal axial dimensions ( $\mathrm{mm}$ ) including length (L), width (W), and thickness $(\mathrm{T})$ of 100 randomly selected seeds of each variety were measured by digital vernier caliper reading to an accuracy of $0.01 \mathrm{~mm}$. 


\subsubsection{Geometric and arithmetic mean diameter}

Geometric mean diameter, Dg (mm), and arithmetic mean diameter, Da $(\mathrm{mm})$ of seeds were calculated using equations (1) and (2) as described by Shah et al. ${ }^{11}$.

$$
D_{g}=\sqrt[3]{L W T}
$$

$$
D_{a}=\frac{L W T}{3}
$$

\subsubsection{Sphericity}

The shape of seeds can be determined in terms of sphericity $(\varphi)$, which is index of roundness and was calculated by the formula used by Ramashia et al. ${ }^{12}$.

$$
\Phi=\frac{\sqrt[3]{L W T}}{L}
$$

Where; L, W, and T are length, width, and thickness of seeds respectively.

\subsubsection{Aspect ratio}

The aspect ratio $\left(\mathrm{R}_{\mathrm{a}}\right)$ was calculated by the equation used by Shah et al. ${ }^{11}$ as:

$$
R_{a}=\frac{W}{L} \times 100
$$

\subsubsection{Volume and surface area}

Sample volume, V $\left(\mathrm{mm}^{3}\right)$, and surface area $\mathrm{S},\left(\mathrm{mm}^{2}\right)$ was calculated from geometric mean diameter by following equation:

$$
\begin{aligned}
& S=\pi \times D_{\mathrm{g}}^{2} \\
& V=\frac{\pi}{6} D_{\mathrm{g}}^{3}
\end{aligned}
$$

\subsubsection{1000-grain weight}

50 seeds were selected randomly and weighed in digital electronic balance (Shimadzu, unic Bloc) of $0.001 \mathrm{~g}$ accuracy. The value was then multiplied by 20 to get the weight of 1000 seeds.

\subsection{Proximate composition of flour}

The moisture (925.10), fat (920.85), ash (923.03), and protein (920.87) contents were determined by official AOAC method ${ }^{26}$.

\subsection{Flour flowability properties}

\subsubsection{Bulk density and tapped density}

Bulk density was measured according to the method described by Gani et al. ${ }^{27}$. The tapped density was determined by the same procedure, but the sample in the measuring cylinder was tapped on the bench very carefully until a constant flour volume was observed.

\subsubsection{Compressibility index and Hausner ratio}

The Compressibility index (CI) and Hausner ratio (HR) were calculated as per the formula given by $\operatorname{Carr}^{28}$.

$$
C I=100 \times\left[1-\frac{\rho_{b}}{\rho_{t}}\right]
$$


Where $\rho_{\mathrm{b}}$ is flour bulk density and $\rho_{\mathrm{t}}$ is flour tapered density.

\subsection{Particle size distribution and polydispersity index}

The particle size distribution of flour samples was measured using a Litesizer 500 laser light scattering instrument (Anton Paar, Australia). 0.01\% flour samples were suspended in Milli-Q water (Elix-10, Millipore, Mosheim, France) and sonicated at $40 \mathrm{kHz}$ (15-30 min) for complete dispersion of flour fractions. The measurements were performed at $20^{\circ} \mathrm{C}$ at neutral $\mathrm{pH}$.

\subsection{Color}

The colour of the flour samples were determined by Color Flex Spectrocolorimeter (Hunter Lab D-25, Ruston, USA) which was calibrated using a white reference tile. The results were expressed in terms of $\mathrm{L}^{*}$ (lightness/brightness), $\mathrm{a}^{*}$ (redness/greenness), and $\mathrm{b}^{*}$ (yellowness/blueness) values.

\subsection{Scanning electron microscopy (SEM)}

The microscopic structure of flour samples were analyzed by scanning electron microscope (Zeiss, EVO 50) under a high vacuum. The samples were mounted on a circular aluminum specimen stub using double-sided adhesive carbon tape. After coating vertically with gold-palladium, the samples were photographed at an accelerator potential of $10.00 \mathrm{kV}$.

\subsection{Thermal characterization of apple seed flours}

The thermal characteristics of flour samples were studied using Mettler Toledo DSC-1 STAR System. Samples $(3.5 \mathrm{mg})$ were weighed into aluminum pans and mixed with Milli Q water $(8 \mu \mathrm{L})$. The pans were sealed hermetically and allowed to equilibrate for $1 \mathrm{~h}$ before analysis. The heat rate was $10{ }^{\circ} \mathrm{C} / \mathrm{min}$ over a temperature range of 20 to $180{ }^{\circ} \mathrm{C}$ in a nitrogen atmosphere. An empty platinum pan was used as the reference. From the curve, enthalpy of gelatinization $(\Delta H)$, the onset (To), peak (Tp), and end (Tc) temperatures were obtained using the data processing software supplied with the DSC instrument.

\subsection{Techno-functional properties}

\subsubsection{Water/oil absorption capacity (WAC/OAC)}

The samples $(1 \mathrm{~g})$ were poured in a pre-weighed centrifuge tube and mixed with $10 \mathrm{~mL}$ of water/oil. The tubes were vortexed for $5 \mathrm{~min}$ and then allowed to stand for $20 \mathrm{~min}$ at room temperature. Thereafter tubes were centrifuged (5810R, Eppendorf, Germany) at $3000 \mathrm{rpm}$ for $30 \mathrm{~min}$ and supernatant (distilled water/oil) decanted and wet residue weighed for determination WAC and OAC.

\subsubsection{Emulsification properties}

Emulsion capacity (EC) and stability (ES) were determined according to the method described by Hussain et al. ${ }^{23}$. Flour samples $(0.5 \mathrm{~g})$ were mixed with $5 \mathrm{ml}$ distilled water in centrifuge tubes and vortexed for $30 \mathrm{~s} .5 \mathrm{ml}$ oil was added to the suspension, homogenized, and then centrifuged at $1100 \mathrm{~g}$ 
for 5 min (Eppendorf, Germany). The emulsification activity expressed in percentage was calculated as:

$$
\text { Emulsion capacity }(\%)=\frac{\mathrm{H} 2-\mathrm{H} 1}{\mathrm{H} 1} \times 100
$$

Where $\mathrm{H}_{2}$ is the height of the emulsified layer in the tube and $\mathrm{H}_{1}$ is the height of total contents before centrifugation

The emulsification stability was estimated by further heating the emulsion for $30 \mathrm{~min}$ at $80{ }^{\circ} \mathrm{C}$ and centrifuged at $1100 \mathrm{~g}$ for $5 \mathrm{~min}$ and expressed as:

$$
\text { Emulsion stability }(\%)=\frac{H t}{H 2} \times 100
$$

Where $\mathrm{H}_{\mathrm{t}}$ is the height of the emulsified layer after heating and $\mathrm{H}_{2}$ is the height of the emulsified layer before heating.

\subsection{Dynamic rheology}

The rheological analysis was carried out using MCR 102 rheometer (ANTON Par, Austria). The flour suspensions $(1 \% \mathrm{w} / \mathrm{v})$ were prepared with Milli-Q water. The suspensions were homogenized at $1000 \times \mathrm{g}$ for $20 \mathrm{~min}$ and thereafter equilibrated at room temperature for $5 \mathrm{~min}$. The homogenized samples were subjected to frequency sweep testing from $0.1-100 \mathrm{rad} / \mathrm{s}$ performed at 25 ${ }^{\circ} \mathrm{C}$ for determining the changes in storage modulus $\left(\mathrm{G}^{\prime}\right)$ and loss modulus $\left(\mathrm{G}^{\prime \prime}\right)$ occurring during the test.

\subsection{Statistical analysis}

All experiments have been carried out in triplicates and data were statistically analyzed by oneway analysis of variance test (ANOVA) using commercial statistical package SPSS version 16.0 (USA) to establish a significant difference between samples ( $\mathrm{p} \leq 0.05$ level). The results reported are expressed as mean \pm standard deviation.

\section{Reference}

1. Purić, M. et al. Application of defatted apple seed cakes as a by-product for the enrichment of wheat bread. LWT 130, 109391 (2020).

2. Candrawinata, V. I., Golding, J. B., Roach, P. D. \& Stathopoulos, C. E. Optimisation of the phenolic content and antioxidant activity of apple pomace aqueous extracts. CyTA-Journal Food 13, 293-299 (2015).

3. Tian, H. L., Zhan, P. \& Li, K. X. Analysis of components and study on antioxidant and antimicrobial activities of oil in apple seeds. Int. J. Food Sci. Nutr. 61, 395-403 (2010).

4. Manzoor, M., Singh, J. \& Gani, A. Characterization of apple (Malus domestica) seed flour for its structural and nutraceutical potential. LWT 112138 (2021) doi:10.1016/J.LWT.2021.112138.

5. $\mathrm{Xu}$, Y. et al. Variation in phenolic compounds and antioxidant activity in apple seeds of seven cultivars. Saudi J. Biol. Sci. 23, 379-388 (2016).

6. Gunes, R., Palabiyik, I., Toker, O. S., Konar, N. \& Kurultay, S. Incorporation of defatted apple 
seeds in chewing gum system and phloridzin dissolution kinetics. J. Food Eng. 255, 9-14 (2019).

7. Sharma, V. et al. Physical properties of tung seed: An industrial oil yielding crop. Ind. Crops Prod. 33, 440-444 (2011).

8. Mansouri, A., Mirzabe, A. H. \& Ráufi, A. Physical properties and mathematical modeling of melon (Cucumis melo L.) seeds and kernels. J. Saudi Soc. Agric. Sci. 16, 218-226 (2017).

9. Malik, M. A. \& Saini, C. S. Engineering properties of sunflower seed: Effect of dehulling and moisture content. Cogent Food Agric. 2, 1145783 (2016).

10. Akintayo, E. T., Adebayo, E. A. \& Arogundade, L. A. Chemical composition, physicochemical and functional properties of akee (Bilphia sapida) pulp and seed flours. Food Chem. 77, 333-336 (2002).

11. Shah, A., Masoodi, F. A., Gani, A. \& Ashwar, B. A. Geometrical, functional, thermal, and structural properties of oat varieties from temperate region of India. J. Food Sci. Technol. 53, 1856-1866 (2016).

12. Ramashia, S. E., Gwata, E. T., Meddows-Taylor, S., Anyasi, T. A. \& Jideani, A. I. O. Some physical and functional properties of finger millet (Eleusine coracana) obtained in subSaharan Africa. Food Res. Int. 104, 110-118 (2018).

13. Li, D. \& Zhu, F. Physicochemical, functional and nutritional properties of kiwifruit flour. Food Hydrocoll. 92, 250-258 (2019).

14. Contreras-Jiménez, B., Torres-Vargas, O. L. \& Rodríguez-García, M. E. Physicochemical characterization of quinoa (Chenopodium quinoa) flour and isolated starch. Food Chem. 298, 124982 (2019).

15. El-safy, S., Salem, R. \& Abd El-Ghany, M. Chemical and Nutritional Evaluation of Different Seed Flours as Novel Sources of Protein. World J Dairy Food Sci.7,59-65 (2012).

16. Kaur, M. \& Singh, N. Studies on functional, thermal and pasting properties of flours from different chickpea (Cicer arietinum L.) cultivars. Food Chem. 91, 403-411 (2005).

17. Sreerama, Y. N., Sashikala, V. B. \& Pratape, V. M. Phenolic compounds in cowpea and horse gram flours in comparison to chickpea flour: Evaluation of their antioxidant and enzyme inhibitory properties associated with hyperglycemia and hypertension. Food Chem. 133, 156162 (2012).

18. Sonawane, S. K., Bagul, M. B., LeBlanc, J. G. \& Arya, S. S. Nutritional, functional, thermal and structural characteristics of Citrullus lanatus and Limonia acidissima seed flours. J. Food Meas. Charact. 10, 72-79 (2016).

19. Hareland, G. A. Evaluation of flour particle size distribution by laser diffraction, sieve analysis and near-infrared reflectance spectroscopy. J. Cereal Sci. 20, 183-190 (1994).

20. Ahmad, M., Gani, A., Masoodi, F. A. \& Rizvi, S. H. Influence of ball milling on the production of starch nanoparticles and its effect on structural, thermal and functional 
properties. Int. J. Biol. Macromol. 151, 85-91 (2020).

21. Alcázar-Alay, S. C. \& Meireles, M. A. A. Physicochemical properties, modifications and

402

403

404

405

406

407

408

409

410

411

412

413

414

415

416

417

418

419

420

421

422

423

424

425

426 applications of starches from different botanical sources. Food Sci. Technol. 35, 215-236 (2015).

22. Ren, Y., Setia, R., Warkentin, T. D. \& Ai, Y. Functionality and starch digestibility of wrinkled and round pea flours of two different particle sizes. Food Chem. 336, 127711 (2021).

23. Hussain, S. Z., Beigh, M. A., Naseer, B. \& Naik, H. R. Visco-thermal and structural characterization of water chestnut flour. J. Food Sci. Technol. 57, 2949-2959 (2020).

24. Jhan, F., Shah, A., Gani, A., Ahmad, M. \& Noor, N. Nano-reduction of starch from underutilised millets: Effect on structural, thermal, morphological and nutraceutical properties. Int. J. Biol. Macromol. 159, 1113-1121 (2020).

25. Marco, C. \& Rosell, C. M. Functional and rheological properties of protein enriched gluten free composite flours. J. Food Eng. 88, 94-103 (2008).

26. AOAC. Association of Official Analytical Chemists. In: Horwitz W (ed.), Official methods of analysis, 17th ed. Washington, D.C., USA (2002).

27. Gani, A. et al. Engineering and functional properties of four varieties of pulses and their correlative study. J. Food Meas. Charact. 9, (2015).

28. Carr, R. L. Evaluating flow properties of solids. Chem. Eng. 18, 163-168 (1965).

\section{Acknowledgment}

Authors are thankful to the Department of Science and Technology, Government of India for award of INSPIRE Fellowship in favor of Ms. Mehnaza Manzoor (Vide Grant No: DST/INSPIREFellowship2017/IF170581) and Department of Food Science and Technology, University of Kashmir for guidance and research facilities.

Author contributions:

Mehnaza Manzoor planned this research work, conducted all the experimental work and also wrote original draft Dr. Jagmohan Singh revised the manuscript.

\section{Competing interests statement}

The authors declare no competing interests.

\section{Additional information}

Correspondence and requests for material should be addressed to M.M .

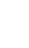

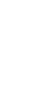


Figures:

438
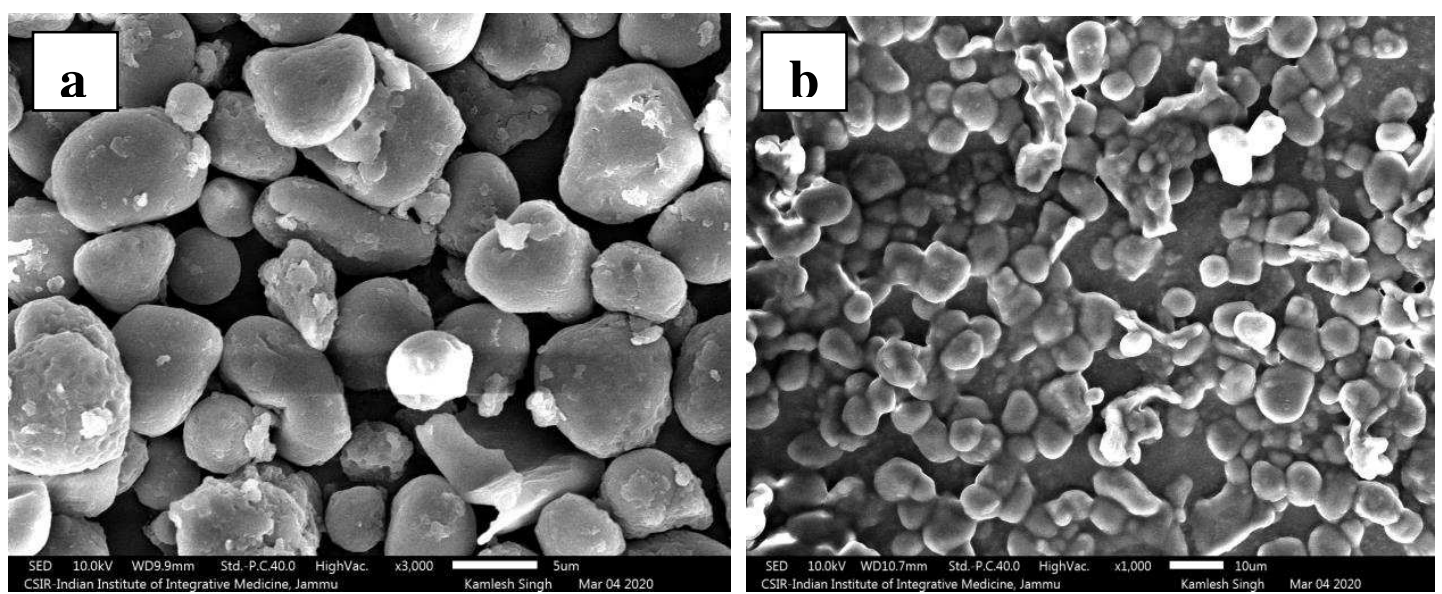

440

Fig. 1 Micrograph of (a) golden delicious seed flour (b) red delicious seed flour at $\mathrm{x} 1 \mathrm{k}$ and $\mathrm{x}$ 441 $3 \mathrm{k}$

442

443

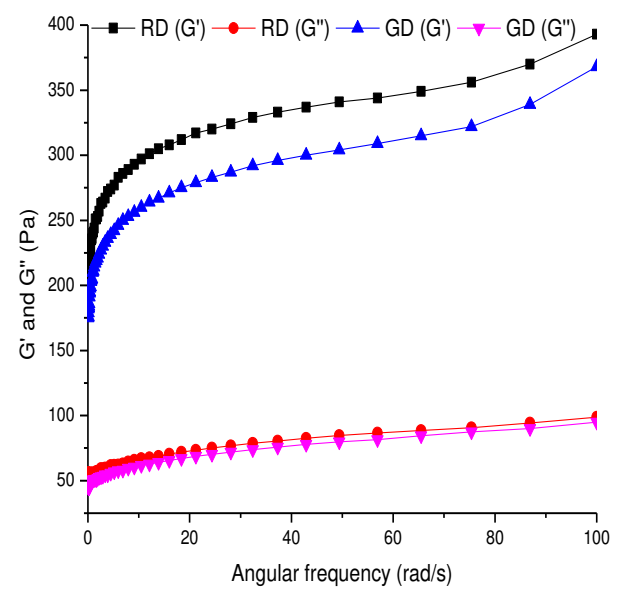

444

445

Fig. 2 Loss $\left(\mathrm{G}^{\prime \prime}\right)$ and storage $\left(\mathrm{G}^{\prime}\right)$ modulus of red $(\mathrm{RD})$ and golden delicious (GD) seed flour

446

447

448

449

450

451

452

453 
Tables:

Table 1 Geometrical properties of apple seeds $(n=3)$

\begin{tabular}{lll}
\hline Parameter & RD & GD \\
\hline Length $(\mathrm{mm})$ & $9.43 \pm 1.07^{\mathrm{a}}$ & $7.69 \pm 0.43^{\mathrm{a}}$ \\
Width (mm) & $4.87 \pm 0.15^{\mathrm{a}}$ & $4.02 \pm 0.01^{\mathrm{b}}$ \\
Thickness (mm) & $2.01 \pm 0.14^{\mathrm{a}}$ & $2.03 \pm 0.13^{\mathrm{a}}$ \\
Geometric mean diameter (mm) & $4.51 \pm 0.20^{\mathrm{a}}$ & $3.97 \pm 0.11^{\mathrm{b}}$ \\
Arithmetic mean diameter $(\mathrm{mm})$ & $5.44 \pm 0.39^{\mathrm{a}}$ & $4.58 \pm 0.15^{\mathrm{b}}$ \\
Seed volume $\left(\mathrm{mm}^{3}\right)$ & $29.08 \pm 3.63^{\mathrm{a}}$ & $20.22 \pm 1.65^{\mathrm{b}}$ \\
Sphericity $(\%)$ & $48.18 \pm 4.06^{\mathrm{a}}$ & $51.72 \pm 2.31^{\mathrm{a}}$ \\
Surface area $\left(\mathrm{mm}^{2}\right)$ & $64.19 \pm 5.95^{\mathrm{a}}$ & $49.57 \pm 2.96^{\mathrm{b}}$ \\
Aspect ratio (\%) & $52.05 \pm 4.73^{\mathrm{a}}$ & $52.38 \pm 2.91^{\mathrm{a}}$ \\
Thousand-grain weight (wt.g) & $45.32 \pm 0.47^{\mathrm{a}}$ & $44.83 \pm 0.22^{\mathrm{a}}$ \\
\hline
\end{tabular}

Different superscript on mean values with standard deviation $( \pm)$ in same row indicates statistical difference $(\mathrm{p} \leq 0.05)$.

$\mathrm{RD}$ and GD represent red delicious seed flour and golden delicious seeds.

Table 2 Physiochemical properties of flour samples $(n=3)$

\begin{tabular}{lllll}
\hline Cultivar & Moisture content (\%) & Protein (\%) & Fat (\%) & Ash (\%) \\
\hline RDF & $8.17 \pm 0.17^{\mathrm{a}}$ & $47.98 \pm 2.04^{\mathrm{a}}$ & $25.31 \pm 0.99^{\mathrm{a}}$ & $4.35 \pm 0.73^{\mathrm{a}}$ \\
GDF & $8.57 \pm 0.25^{\mathrm{a}}$ & $41.31 \pm 2.52^{\mathrm{b}}$ & $21.47 \pm 1.12^{\mathrm{b}}$ & $4.67 \pm 0.60^{\mathrm{a}}$ \\
\hline
\end{tabular}

Different superscript on mean values with standard deviation $( \pm)$ in same column indicates statistical difference $(\mathrm{p} \leq 0.05)$.

RDF and GDF represent red delicious seed flour and golden delicious seeds.

Table 3 Particle size distribution and average hydrodynamic particle size and flowability properties of flour samples $(n=3)$

\begin{tabular}{lll}
\hline Parameter & RDF & GDF \\
\hline Particle size distribution $(\boldsymbol{\mu m})$ & & \\
Dv(10) & $6.26 \pm 2.20^{\mathrm{a}}$ & $2.60 \pm 3.910^{\mathrm{b}}$ \\
$\mathrm{Dv}(50)$ & $7.58 \pm 3.80^{\mathrm{a}}$ & $4.41 \pm 2.90^{\mathrm{b}}$ \\
$\operatorname{Dv}(90)$ & $9.06 \pm 1.10^{\mathrm{a}}$ & $6.12 \pm 2.30^{\mathrm{b}}$ \\
Average hydrodynamic particle size $(\boldsymbol{\mu m})$ & $8.73 \pm 4.10^{\mathrm{a}}$ & $2.97 \pm 2.10^{\mathrm{b}}$ \\
Polydispersity index & $0.43 \pm 2.10^{\mathrm{a}}$ & $0.12 \pm 1.10^{\mathrm{b}}$ \\
Flowability properties & & \\
Bulk density (g/mL) & $0.38 \pm 0.10^{\mathrm{a}}$ & $0.604 \pm 0.09^{\mathrm{b}}$ \\
Tapped density $(\mathrm{g} / \mathrm{mL})$ & $0.58 \pm 0.17^{\mathrm{a}}$ & $0.69 \pm 0.13^{\mathrm{b}}$ \\
Carr's index $(\%)$ & $34.51 \pm 2.99^{\mathrm{a}}$ & $37.70 \pm 1.62^{\mathrm{a}}$ \\
Hausner ratio $(\%)$ & $1.52 \pm 0.06^{\mathrm{a}}$ & $1.6 \pm 0.04^{\mathrm{a}}$ \\
\hline
\end{tabular}


Different superscripts on mean values with standard deviation $( \pm)$ in same row indicate statistical difference $(\mathrm{p} \leq 0.05)$.

473 Dv (10), Dv (50) and Dv (90) symbolize the points in the size distribution upto which $10 \%$, $50 \%$ and $90 \%$ of total volume of material in sample is contained.

RDF and GDF represent red delicious seed flour and golden delicious seed flour.

Table 4 Color, thermal properties and techno-functional properties of flour samples (n $480=3$ )

\begin{tabular}{lll}
\hline Parameter & RDF & GDF \\
\hline Color & & \\
$\mathrm{L}^{*}$ & $76.87 \pm 0.52^{\mathrm{b}}$ & $78.93 \pm 1.02^{\mathrm{a}}$ \\
$\mathrm{a}^{*}$ & $0.97 \pm 0.01^{\mathrm{b}}$ & $1.31 \pm 0.12^{\mathrm{a}}$ \\
$\mathrm{b}^{*}$ & $9.18 \pm 0.41^{\mathrm{b}}$ & $10.64 \pm 0.37^{\mathrm{a}}$ \\
Thermal properties & & \\
Onset temperature $\left({ }^{\circ} \mathrm{C}\right)$ & $89.07 \pm 2.94^{\mathrm{a}}$ & $78.95 \pm 1.69^{\mathrm{b}}$ \\
Peak temperature $\left({ }^{\circ} \mathrm{C}\right)$ & $102.17 \pm 2.15^{\mathrm{a}}$ & $98.37 \pm 1.25^{\mathrm{b}}$ \\
Conclusion temperature $\left({ }^{\circ} \mathrm{C}\right)$ & $117.53 \pm 1.66^{\mathrm{a}}$ & $108.71 \pm 2.49^{\mathrm{b}}$ \\
Enthalpy of gelatinization $(\mathrm{J} / \mathrm{g})$ & $18.41 \pm 0.63^{\mathrm{a}}$ & $9.78 \pm 1.33^{\mathrm{b}}$ \\
Technofunctional properties & & \\
WHC $(\mathrm{g} / 100 \mathrm{~g})$ & $327.65 \pm 1.43^{\mathrm{a}}$ & $312.58 \pm 1.57^{\mathrm{b}}$ \\
OHC $(\mathrm{g} / 100 \mathrm{~g})$ & $92.97 \pm 2.04^{\mathrm{a}}$ & $86.76 \pm 1.74^{\mathrm{b}}$ \\
EA $(\%)$ & $79.61 \pm 1.43^{\mathrm{a}}$ & $72.01 \pm 0.62^{\mathrm{b}}$ \\
ES $(\%)$ & $51.81 \pm 1.07^{\mathrm{a}}$ & $46.56 \pm 1.17^{\mathrm{b}}$ \\
\hline
\end{tabular}

Results are mean \pm standard deviation.

Mean values with different letters in the same row indicate a statistical difference $(\mathrm{p} \leq 0.05)$. seed flour, water holding capacity, oil holding capacity, emulsion activity, and emulsion stability, respectively. 


\section{Supplementary Files}

This is a list of supplementary files associated with this preprint. Click to download.

- Graphicalabstract3.jpg 